\title{
Acute emesis: moderately emetogenic chemotherapy
}

\author{
Jørn Herrstedt • Bernardo Rapoport • David Warr • \\ Fausto Roila • Emilio Bria • Cynthia Rittenberg • \\ Paul J. Hesketh
}

Received: 29 March 2010 /Accepted: 2 July 2010 /Published online: 2 August 2010

(C) Springer-Verlag 2010

\begin{abstract}
This paper is a review of the recommendations for the prophylaxis of acute emesis induced by moderately emetogenic chemotherapy as concluded at the third Perugia Consensus Conference, which took place in June 2009. The review will focus on new studies appearing since the
\end{abstract}

\author{
J. Herrstedt $(\bowtie)$ \\ Department of Oncology, Odense University Hospital, \\ 5000 Odense, Denmark \\ e-mail: herrstedt@dadlnet.dk \\ B. Rapoport \\ The Medical Oncology Centre of Rosebank, \\ Johannesburg, South Africa \\ e-mail: brapoport@icon.co.za \\ D. Warr \\ Princess Margaret Hospital, University of Toronto, \\ Toronto, Canada \\ e-mail: david.warr@uhn.on.ca \\ F. Roila \\ Medical Oncology, Santa Maria Hospital, \\ Terni, Italy \\ e-mail: roila.fausto@libero.it \\ E. Bria \\ Department of Medical Oncology, \\ Regina Elena National Cancer Institute, \\ Rome, Italy \\ e-mail: emiliobria@yahoo.it \\ C. Rittenberg \\ Rittenberg Oncology Consulting, \\ Metairie, LA, USA \\ e-mail: cindyrit@bellsouth.net \\ P. J. Hesketh \\ Lahey Clinic, \\ Burlington, MA, USA \\ e-mail: phesketh@aol.com
}

Second consensus conference in April 2004. The following issues will be addressed: dose and schedule of antiemetics, different groups of antiemetics such as corticosteroids, serotonin $_{3}$ receptor antagonists, dopamine 2 receptor antagonists, and neurokinin ${ }_{1}$ receptor antagonists. Furthermore, antiemetic prophylaxis in patients receiving multiple cycles of moderately emetogenic chemotherapy will be reviewed. Consensus statements are given, including optimal dose and schedule of $\operatorname{serotonin}_{3}$ receptor antagonists, dexamethasone, and neurokinin $n_{1}$ receptor antagonists. The most significant recommendations (and changes since the 2004 version of the guidelines) are as follows: the best prophylaxis in patients receiving moderately emetogenic chemotherapy (not including a combination of an anthracycline plus cyclophosphamide) is the combination of palonosetron and dexamethasone on the day of chemotherapy, followed by dexamethasone on days $2-3$. In patients receiving a combination of an anthracycline plus cyclophosphamide, a combination of a $\operatorname{serotonin}_{3}$ receptor antagonist plus dexamethasone, plus the neurokinin ${ }_{1}$ receptor antagonist aprepitant on the day of chemotherapy, followed by aprepitant days $2-3$, is recommended.

Keywords Serotonin antagonists · Neurokinin antagonists · Dexamethasone $\cdot$ Anthracycline $\cdot$ Cyclophosphamide . Chemotherapy

\section{Background}

In patients receiving moderately emetogenic chemotherapy (MEC), the most interesting studies in the period from 2004-2009 investigated patients receiving a combination of an anthracycline plus cyclophosphamide. These cytostatics are ranked as moderately emetogenic when given as single 
agents, whereas, the combination seems to be as emetogenic as cisplatin. A few studies have focused on patients receiving other kinds of chemotherapy such as oxaliplatin and irinotecan.

Since the last consensus conference in 2004, three large and one small phase III study including patients receiving chemotherapy with a combination of an anthracycline plus cyclophosphamide, have investigated the addition of one of the neurokinin ${ }_{1}$ receptor antagonists (aprepitant or casopitant) to the combination of the serotonin $_{3}$ receptor antagonist, ondansetron plus dexamethasone. Also, a large phase III study comparing palonosetron with granisetron, both combined with dexamethasone, has been published.

\section{Current practice guidelines for prophylaxis of acute emesis induced by MEC}

The Multinational Association of Supportive Care in Cancer (MASCC), American Society of Clinical Oncology (ASCO), National Comprehensive Cancer Network (NCCN), and the European Society of Medical Oncology (ESMO) practice guidelines for prophylaxis of acute emesis following MEC are summarized in Table 1. ASCO published their last update in 2006 [10], as did MASCC [1]. MASCC does, however, update the recommendations every 6 months on the website (www.mascc.org). ESMO publishes an annual update in the Annals of Oncology [6], and NCCN update their recommendations annually on their website [13].

The recommendations in Table 1 include the latest update from journals or websites. All guidelines in 2004 agreed that a 5 -hydroxytryptamine type $3\left(5-\mathrm{HT}_{3}\right)$-receptor antagonist, in combination with a corticosteroid (dexamethasone), was the treatment of choice. An exception was patients receiving a combination of cyclophosphamide plus an anthracycline. For these patients, the addition of the neurokinin $1\left(\mathrm{NK}_{1}\right)$-receptor antagonist, aprepitant, was recommended.

\section{Literature search strategy}

Current guidelines references were used as the basis for the selected references up to year 2004. A Pubmed/Medline search (from 2004 to 2009, June 1) was conducted of articles written in English and using the search terms: "acute emesis" and "chemotherapy" (limited to: humans, adults, cancer (topic), clinical trial, review, meta-analysis, practice guideline, and randomized controlled trial). The abstracts were accessed, and relevant references were selected by headline and then by abstract. An additional number of PubMed/Medline searches were completed using the terms "acute emesis" and using an antiemetic as the second search term. The antiemetic search terms used included: ondansetron, granisetron, dolasetron, tropisetron, ramosetron, azasetron, palonosetron, metoclopramide, prochlorperazine, metopimazine, domperidone, dexamethasone, prednisolone, methylprednisolone, prednisone, benzodiazepines, cannabinoids, aprepitant, and casopitant. Furthermore, Medline searches, using the term "acute emesis" and using the chemotherapy agent as the second search term, were also done. The chemotherapy terms used included: anthracyclines, doxorubicin, epirubicin, cyclophosphamide, carboplatin, irinotecan, oxaliplatin, and ifosfamide. All references were reviewed, but primarily, studies adding new knowledge to the previous guidelines of MASCC, ESMO, ASCO, and NCCN respectively, were included in the reference list of this paper. Randomized, double-blind studies were scored as having the highest scientific level. (Table 2)

Table 1 Current consensus guideline recommendations for prophylaxis of acute CINV

\begin{tabular}{|c|c|c|}
\hline Group & Recommendation & $\begin{array}{l}\text { MASCC levels of confidence } \\
\text { and consensus }\end{array}$ \\
\hline MASCC [4] & \multirow{2}{*}{$\begin{array}{l}\text { MEC, not including a combination of an anthracycline plus cyclophosphamide: } \\
5-\mathrm{HT}_{3} \text { receptor antagonist plus dexamethasone. }\end{array}$} & \multirow{6}{*}{$\begin{array}{l}\text { Level of confidence: high } \\
\text { Level of consensus: high } \\
\text { Level of confidence: moderate } \\
\text { Level of consensus: high }\end{array}$} \\
\hline ASCO [5] & & \\
\hline ESMO [7] & $\begin{array}{l}\text { MEC, including a combination of an anthracycline plus cyclophosphamide: } \\
5-\mathrm{HT}_{3} \text { receptor antagonist plus dexamethasone plus aprepitant. }\end{array}$ & \\
\hline \multirow[t]{3}{*}{ NCCN (25) } & MEC & \\
\hline & $\begin{array}{l}\text { 5- } \mathrm{HT}_{3} \text { receptor antagonist plus dexamethasone. } \\
\text { For select patients, e.g. those receiving carboplatin } \geq 300 \mathrm{mg} / \mathrm{m}^{2}, \\
\text { cyclophosphamide } \geq 600-1,000 \mathrm{mg} / \mathrm{m}^{2} \text { and doxorubicin } \geq 50 \mathrm{mg} / \mathrm{m}^{2} \text {, } \\
\text { aprepitant or fosaprepitant can be added. }\end{array}$ & \\
\hline & $\begin{array}{l}\text { Lorazepam and a } \mathrm{H}_{2} \text { blocker or proton pump inhibitor can be } \\
\text { added (or not) in all patients. }\end{array}$ & \\
\hline
\end{tabular}


Table 2 Doses of antiemetics when given on day 1 of prophylaxis in moderately emetogenic chemotherapy

\begin{tabular}{lll}
\hline 5-HT 3 receptor antagonists & Oral dose & Intravenous dose \\
\hline Ondansetron & $8 \mathrm{mg}$ bid or $16 \mathrm{mg} \mathrm{qd}$ & $8 \mathrm{mg} \mathrm{qd}$ \\
Granisetron & $2 \mathrm{mg} \mathrm{qd}$ & $1 \mathrm{mg} \mathrm{qd}$ \\
Dolasetron & $100-200 \mathrm{mg} \mathrm{qd}$ & $1.8 \mathrm{mg} / \mathrm{kg} \mathrm{qd}$ \\
Tropisetron & $5 \mathrm{mg} \mathrm{qd}$ & $5 \mathrm{mg} \mathrm{qd}$ \\
Palonosetron & $0.5 \mathrm{mg} \mathrm{qd}$ & $0.25 \mathrm{mg} \mathrm{qd}$ \\
\hline
\end{tabular}

$\mathrm{NK}_{1}$ receceptor antagonists

\begin{tabular}{lll}
\hline $\begin{array}{l}\text { Aprepitant } \\
\text { Casopitant }\end{array}$ & $\begin{array}{l}125 \mathrm{mg} \mathrm{qd} \\
150 \mathrm{mg} \mathrm{qd}\end{array}$ & $\begin{array}{l}115 \mathrm{mg} \mathrm{qd} \text { (fosaprepitant) } \\
90 \mathrm{mg} \mathrm{qd}\end{array}$ \\
\hline Corticosteroids & Oral dose & Intravenous dose \\
\hline Dexamethasone & $8 \mathrm{mg} \mathrm{qd}$ & $8 \mathrm{mg} \mathrm{qd}$ \\
\hline
\end{tabular}

\section{Overview of literature}

Studies in patients receiving multiple-day chemotherapy and studies in patients with refractory emesis or with breakthrough emesis are not included in this review.

Since the publication of the 2004 guidelines, studies confirming the optimal dose of the intravenous formulation of aprepitant, fosaprepitant have been published.

In patients treated with MEC, several phase II and a large phase III study investigating the $5-\mathrm{HT}_{3}$-receptor antagonist, palonosetron, have been published, as have a number of phase II and phase III studies with the neurokinin ${ }_{1}$-receptor antagonists, aprepitant and casopitant (Table 3).

\section{Dose and schedule}

Recommended doses of antiemetic agents are given in Table 2. Except for the dose of dexamethasone (now $8 \mathrm{mg} \times 1$ on day 1 of chemotherapy) when given in combination with a $\mathrm{NK}_{1}$ receptor antagonist and the addition of the recommended dose of fosaprepitant, there are no changes in the recommendations as compared with the 2004 recommendations.

When oral dexamethasone $20 \mathrm{mg}$ is administered concomitantly with oral aprepitant $125 \mathrm{mg}$, the bioavailability of dexamethasone ( $0-24 \mathrm{~h})$ is increased 2.2-fold as compared to the same dose of dexamethasone without concomitant aprepitant. To obtain the same bioavailability (0-24 h) when administered concomitantly with aprepitant, the dose of oral dexamethasone was decreased to $12 \mathrm{mg}$ on day 1 in phase III studies [12]. Accordingly, the dose of intravenous methylprednisolone should be reduced one fourth, when administered concomitantly with aprepitant [12].

The impact of casopitant on the pharmacokinetics of dexamethasone also has been investigated [9, 15]. As with aprepitant, a single dose of oral casopitant $150 \mathrm{mg}$ increases the bioavailability of oral dexamethasone. The bioavailability of intravenous dexamethasone is increased by $21 \%$ if coadministered with oral casopitant $150 \mathrm{mg}$ [15]. Because a randomized study [8] has demonstrated that a single dose of dexamethasone $8 \mathrm{mg}$ is as good as higher doses, the consensus panel recommends that a single dose of dexamethasone is used, also when given in a combination with a neurokinin antagonist.

The recommended oral dose of aprepitant is $125 \mathrm{mg} \times 1$, and the intravenous dose of fosaprepitant is $115 \mathrm{mg} \times 1$ [10]. The oral and intravenous doses of casopitant used in phase III studies were 150 and $90 \mathrm{mg} \times 1$, respectively [15].

\section{Corticosteroids}

The corticosteroids were described in detail in the last review paper from the Perugia Consensus Conference in 2004 [4]. As concluded in 2004, corticosteroids improve the efficacy of all the serotonin $_{3}$-receptor antagonists. The inclusion of dexamethasone in three-drug combinations with a neurokinin $_{1}$-receptor antagonist will be described later.

No new randomized studies, specifically addressing the effect of corticosteroids in acute nausea and vomiting induced by MEC, have been published since the last update. The recommended doses of dexamethasone as part

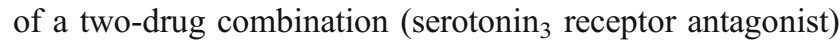
and a three-drug combination (serotonin ${ }_{3}$ receptor antagonist plus a neurokinin ${ }_{1}$-receptor antagonist) are given in the consensus statement at the end of this paper.

\section{$5-\mathrm{HT}_{3}$ receptor antagonists}

The $5-\mathrm{HT}_{3}$ receptor antagonists ondansetron, granisetron, dolasetron, tropisetron, and palonosetron were all reviewed in the previous guidelines. In 2004, there was consensus 


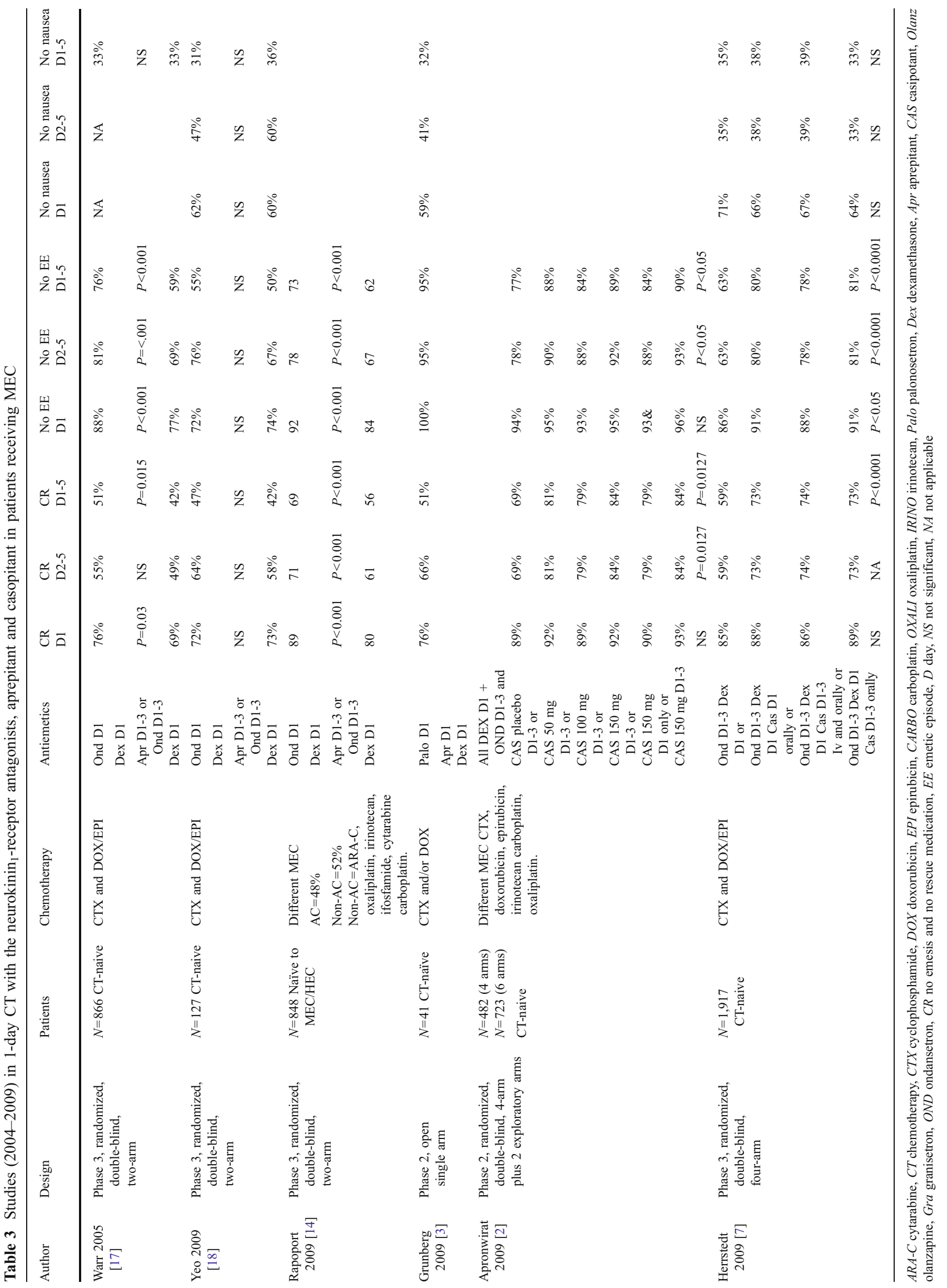


that no clinically meaningful differences existed between the agents for acute $(0-24 \mathrm{~h})$ efficacy and toxicity in MEC.

Since then, a number of small studies have investigated palonosetron in patients receiving MEC and different combinations of antiemetics. Because these studies included a limited number of patients, did not include a control arm, or used an open design, these studies do not lead to a change in the updated guidelines.

Recently, a randomized, double-blind study compared the antiemetic effect of granisetron plus dexamethasone with palonosetron plus dexamethasone in patients receiving cisplatin-based chemotherapy $\left(\geq 50 \mathrm{mg} / \mathrm{m}^{2}\right)$ or a combination of an anthracycline plus cyclophosphamide (AC) [16]. Stratification was done for chemotherapy, gender, and age ( $<55$ years or $\geq 55$ years). The mean doses of chemotherapy were the same in the two arms. The hypothesis was that palonosetron was non-inferior to granisetron in the acute phase and superior in the delayed phase for the primary endpoint ( $\mathrm{CR}=$ no emesis and no need for rescue antiemetics). With a CR $(0-24 \mathrm{~h})$ of $75.3 \%$ versus $73.3 \%(p=\mathrm{NS})$ and a CR $(24-120$ h) of $56.8 \%$ versus $44.5 \%(p<0.0001)$, the hypothesis was confirmed. In the AC/EC subpopulation, the $\mathrm{CR}$ rates were $69.0 \%$ versus $64.8 \%(0-24 \mathrm{~h}, p=\mathrm{NS})$ and $61.1 \%$ versus $50.0 \%(24-120 \mathrm{~h}, p=0.0165)$, respectively. Because guidelines recommend that aprepitant is used in combination with a $5-\mathrm{HT}_{3}$ receptor antagonist plus dexamethasone in patients treated with AC chemotherapy, this study does not change the recommendations for the first $24 \mathrm{~h}$ after initiation of $\mathrm{AC}$. If a $\mathrm{NK}_{1}$ receptor antagonist is not available, palonosetron is the preferred $5-\mathrm{HT}_{3}$ receptor antagonist, in combination with dexamethasone, in patients treated with AC. A majority of the consensus panel $(70 \%)$ also agreed that palonosetron should be the preferred $5-\mathrm{HT}_{3}$ receptor antagonist in nonAC MEC. These recommendations are based on the above study and accumulating evidence from other phase II and III studies.

\section{Dopamine receptor antagonists}

The role of dopamine receptor antagonists in the prophylaxis of acute emesis from MEC seems to be limited to (1) patients with refractory emesis after previous antiemetic therapy with a combination of a 5$\mathrm{HT}_{3}$ receptor antagonist plus a corticosteroid or (2) patients who are not suitable for treatment with corticosteroids. In the daily clinical practice, dopamine antagonists are also used in patients with breakthrough emesis, but this indication has not been investigated in a randomized trial.

\section{Other antiemetics}

These include benzodiazepines and cannabinoids. No new studies, with an impact to change the recommendations, have been published since 2004 .

\section{$\mathrm{NK}_{1}$ receptor antagonists}

Since 2004, three phase III studies investigating aprepitant $[14,17,18]$ and one phase II [2] and one phase III [7] study investigating casopitant in MEC have been published. The results of the first phase III aprepitant study [17] already has led to an update on the MASCC website, recommending the addition of aprepitant to the combination of a $5-\mathrm{HT}_{3}$-receptor antagonist plus dexamethasone in patients receiving a combination of cyclophosphamide plus an anthracycline. Another study with a small sample size did not show any advantage of aprepitant in addition to ondansetron plus dexamethasone, but given the small sample size, this study was underpowered [18].

A recent, large phase III randomized, gender-stratified, double-blind trial in 848 patients receiving a broad range of MEC regimens (non-AC or AC) with a variety of tumor types showed superiority of an aprepitant triple regimen compared to a control regimen of ondansetron and dexamethasone [14]. The primary efficacy endpoint was the proportion of patients reporting no vomiting during the 5 days $(0-120 \mathrm{~h})$ following initiation of chemotherapy. Significantly more patients in the aprepitant group reported no vomiting compared to the control group $72.6 \%$ versus $62.1 \%(p<0.001)$. Also in the acute and delayed phases, significantly more patients in the aprepitant group reported no vomiting compared to the control group ( $92 \%$ versus $83.7 \%(p<0.001))$ and $77.9 \%$ versus $66.8 \%(p<0.001)$, respectively. The key secondary endpoint was the overall complete response (no emetic episodes and no administration of rescue therapy) during the 5 days $(0-120 \mathrm{~h})$ following initiation of chemotherapy. Significantly more patients in the aprepitant group reported complete response compared to the control group $(68.7 \%$ vs. $56.3 \%, p<0.001)$. In addition, significantly more patients in the aprepitant group reported complete response compared to the control group in both the acute and delayed phases $(89.2 \%$ versus $80.3 \%, p<$ 0.01 and $70.8 \%$ versus $60.9 \%, p<0.01$ ), respectively. No significant differences in the incidence of adverse events were identified. This study confirms and reinforces the results from the first phase III MEC study in breast cancer patients treated with $\mathrm{AC}$ chemotherapy. Because the analysis in the $\mathrm{AC}$ and non-AC populations were post hoc analyses, and because of the heterogeneity of chemotherapy in the non-AC population, this study is 
not considered sufficiently compelling to recommended the standard use of aprepitant with the initial cycle of nonAC chemotherapy.

Fosaprepitant is an intravenous pro-drug of aprepitant. Pharmacological data have been published, but no randomized trials using this formulation have been published [11].

A casopitant phase II study [2] included four study arms and two exploratory arms. Patients $(n=723)$ were chemotherapy-naïve and received cyclophosphamide 500$1,500 \mathrm{mg} / \mathrm{m}^{2}$ if given with other MEC; cyclophosphamide $750-1,500 \mathrm{mg} / \mathrm{m}^{2}$ if given alone, or with agents with minimal or low emetogenic potential; oxaliplatin $\geq 85 \mathrm{mg} / \mathrm{m}^{2}$; doxorubicin $\geq 60 \mathrm{mg} / \mathrm{m}^{2}$; epirubicin $\geq 90 \mathrm{mg} / \mathrm{m}^{2}$; irinotecan or carboplatin $A U C \geq 5$. All patients received ondansetron (days 1-3) plus dexamethasone (day 1) for antiemetic protection. Patients were then randomized to receive, in addition oral placebo, casopitant $50 \mathrm{mg}, 100 \mathrm{mg}$, or $150 \mathrm{mg} /$ day (days 1-3). The two exploratory arms evaluated, respectively, a 1-day casopitant regimen $(150 \mathrm{mg})$ and a once-daily ondansetron plus casopitant regimen. Primary endpoints were the $\mathrm{CR}$ rates (no vomiting, retching, rescue therapy, or premature discontinuation) and significant nausea ( $\geq 25 \mathrm{~mm}$ on visual analog scale) over the first $120 \mathrm{~h}$ following cycle 1 of MEC for groups 1-4. No statistics were planned on the data from the first $24 \mathrm{~h}$, but the CR rate in the control group was $89.3 \%$, as compared to $89.3-91.7 \%$ in the casopitant arms. CR rates were also comparable in the two exploratory arms. No significant differences in the protection from nausea were seen. Very few patients vomited within the first $24 \mathrm{~h}$ after MEC (4.1-6.7\%).

The casopitant phase III study [7] used a randomized, double-blind, four-arm parallel design. Patients $(n=1,933)$ received cyclophosphamide IV $\left(500-1,500 \mathrm{mg} / \mathrm{m}^{2}\right)$ and doxorubicin IV $\left(\geq 40 \mathrm{mg} / \mathrm{m}^{2}\right)$, or cyclophosphamide IV $\left(500-1,500 \mathrm{mg} / \mathrm{m}^{2}\right)$, and epirubicin IV $\left(\geq 60 \mathrm{mg} / \mathrm{m}^{2}\right)$. Administration of additional chemotherapy was allowed if the additional agent(s) was of low or minimal emetogenic potential. All patients received dexamethasone $8 \mathrm{mg}$ IV on day 1 and oral ondansetron $8 \mathrm{mg}$ twice daily on days 1-3. Patients were randomized to a control arm (placebo), a single oral dose casopitant arm (150 mg oral, day 1), a 3-day oral casopitant arm (150 mg oral day $1+$ $50 \mathrm{mg}$ orally (PO) days 2-3), or a 3-day IV/oral casopitant arm (90 mg IV day $1+50 \mathrm{mg}$ PO days 2-3). The primary endpoint was the proportion of patients achieving complete response (no vomiting/retching or rescue medications) in the first $120 \mathrm{~h}$ after the initiation of MEC. A significantly greater proportion of patients in the single dose oral casopitant arm, 3-day oral casopitant arm, and 3-day IV/oral casopitant arm achieved complete response $(73 \%, 73 \%$, and $74 \%$, respectively) versus control $(59 \% ; p<0.0001)$. The study did not demonstrate a reduced proportion of patients with nausea in those receiving casopitant. There was no difference during the first $24 \mathrm{~h}$ in the number of patients with $\mathrm{CR}$. The number of patients without vomiting was significantly superior to the control arm (86\%), as compared to the two oral arms (91\% in both, $p=0.0428$ and 0.0131 , respectively), but not to the iv/oral arm (88\%). The singleday oral casopitant arm was as effective as the 3-day oral and iv/oral arms.

After the completion of the consensus conference, GlaxoSmithKline decided to discontinue the regulatory filings for casopitant. Consequently, casopitant cannot be recommended by the consensus panel, but the results of the casopitant studies contribute to the conclusions about neurokinin $_{1}$ receptor antagonists as a drug class.

\section{Multiple cycles of MEC}

The first phase III MEC study investigating the effect of aprepitant followed patients through a maximum of four cycles of AC chemotherapy. The aprepitant arm was significantly superior to the control arm during all cycles with a sustained no emesis rate of $39 \%$ versus $63 \%$ ( $p=$ $0.0001)$ [5].

\section{Conclusion}

Since the last consensus conference in 2004, a number of phase II and III studies $[2,7,14,17,18]$ have confirmed the use of a $\mathrm{NK}_{1}$ receptor antagonist, in combination with a 5$\mathrm{HT}_{3}$ receptor antagonist plus dexamethasone, in patients receiving chemotherapy, including a combination of an anthracycline plus cyclophosphamide. There seems to be no major differences between the $\mathrm{NK}_{1}$ receptor antagonists, aprepitant and casopitant, although a phase III study [6] demonstrated that casopitant can be given as a single oral dose with the same efficacy as 3-day regimens. A small non comparative study has however indicated that aprepitant can also be effective, when given in a single oral dose [3].

The study by Saito et al. [16] is interesting because this is the first time palonosetron has been compared to granisetron in a randomized trial. The design of the study (including both cisplatin and AC-based chemotherapy, and the lack of a $\mathrm{NK}_{1}$ receptor antagonist in the antiemetic regimens) limits the ability of the study to change the recommendations in the current guidelines. Randomized studies comparing palonosetron with another $5-\mathrm{HT}_{3}$ receptor antagonist both combined with a $\mathrm{NK}_{1}$ receptor 
antagonist and dexamethasone in the setting of cisplatin and AC-based chemotherapy are highly warranted.

The consensus statements concerning patients receiving moderately emetogenic chemotherapy are listed at the end of this paper. It is indicated if a statement is new or has been changed, as compared to the 2004 consensus document [4].

\section{Consensus Statements 2009}

Statements 1, 4, 5, 6, 7 and 9 have been changed or are new. MASCC level of confidence and consensus defined in Ann Oncol 1998;9:811-19.

1. Palonosetron plus dexamethasone is recommended for prophylaxis of acute nausea and vomiting in patients, who receive MEC not including a combination of an anthracycline plus cyclophosphamide (changed from 2004).

MASCC level of confidence: Moderate level of consensus: Moderate ESMO level of evidence: II grade of recommendation: B

2. A $5-\mathrm{HT}_{3}$ receptor antagonist plus dexamethasone plus the $\mathrm{NK}_{1}$ receptor antagonist, aprepitant is recommended for prophylaxis of acute nausea and vomiting in patients, who receive MEC including a combination of an anthracycline plus cyclophosphamide (unchanged from 2004).

\begin{tabular}{ll}
\hline MASCC level of confidence: High & level of consensus: High \\
ESMO level of evidence: I & grade of recommendation: A
\end{tabular}

3. There is no difference in the effectiveness of oral or intravenous administration of a $5-\mathrm{HT}_{3}$ receptor antagonist (unchanged from 2004).

\begin{tabular}{ll}
\hline MASCC level of confidence: High & $\begin{array}{l}\text { level of consensus: High } \\
\text { grade of recommendation: A }\end{array}$ \\
\hline
\end{tabular}

4. Recommended doses of serotonin antagonists in MEC (changed from 2004)

The recommended oral dose of ondansetron in MEC is $16 \mathrm{mg}^{*}$

\begin{tabular}{ll}
\hline MASCC level of confidence: High & level of consensus: High \\
ESMO level of evidence: I & grade of recommendation: A
\end{tabular}

*Randomized studies have tested the $8 \mathrm{mg}$ twice daily schedule
The recommended intravenous dose of ondansetron in $\mathrm{MEC}$ is $8 \mathrm{mg}$ or $0.15 \mathrm{mg} / \mathrm{kg} \times 1$

MASCC level of confidence: Moderate level of consensus: High

ESMO level of evidence: III

grade of recommendation: $\mathrm{B}$

The recommended oral dose of granisetron in MEC is $2 \mathrm{mg} \times 1$.

\begin{tabular}{ll}
\hline MASCC level of confidence: High & $\begin{array}{l}\text { level of consensus: High } \\
\text { grade of recommendation: A }\end{array}$ \\
\hline
\end{tabular}

The recommended intravenous dose of granisetron in $\mathrm{MEC}$ is $1 \mathrm{mg}$ or $0.01 \mathrm{mg} / \mathrm{kg} \times 1$

\begin{tabular}{ll}
\hline MASCC level of confidence: High & $\begin{array}{l}\text { level of consensus: High } \\
\text { grade of recommendation: A }\end{array}$ \\
\hline
\end{tabular}

The recommended oral dose of dolasetron in MEC is $100 \mathrm{mg} \times 1$

MASCC level of confidence: Moderate level of consensus: High ESMO level of evidence: II grade of recommendation: A

The recommended intravenous dose of dolasetron in $\mathrm{MEC}$ is $100 \mathrm{mg}$ or $1.8 \mathrm{mg} / \mathrm{kg} \times 1$

MASCC level of confidence: Moderate level of consensus: High ESMO level of evidence: II grade of recommendation: A

The recommended oral dose of tropisetron in MEC is $5 \mathrm{mg} \times 1$

\begin{tabular}{ll}
\hline MASCC level of confidence: low & $\begin{array}{l}\text { level of consensus: High } \\
\text { grade of recommendation: B }\end{array}$ \\
\hline
\end{tabular}

The recommended intravenous dose of tropisetron in $\mathrm{MEC}$ is $5 \mathrm{mg} \times 1$

MASCC level of confidence: Moderate level of consensus: High ESMO level of evidence: III grade of recommendation: B

The recommended oral dose of palonosetron is $0.50 \mathrm{mg} \times 1$ (new since 2004)

MASCC level of confidence: Moderate level of consensus:High ESMO level of evidence: II grade of recommendation: A 
The recommended intravenous dose of palonosetron is $0.25 \mathrm{mg} \times 1$

MASCC level of confidence: High

ESMO level of evidence: I grade level of consensus: High

of recommendation: A

5. There are no clinically relevant differences in the toxicity of the $5-\mathrm{HT}_{3}$ receptor antagonists (unchanged from 2004)

MASCC level of confidence: High

ESMO level of evidence: I

6. Recommended dose of dexamethasone in MEC (new since 2004)

The recommended dose of dexamethasone administered in a two-drug combination with a 5- $\mathrm{HT}_{3}$ receptor antagonist or in a three-drug combination with a $5-\mathrm{HT}_{3}$ receptor antagonist and a $\mathrm{NK}_{1}$ receptor antagonist for prophylaxis of acute nausea and vomiting from MEC is $8 \mathrm{mg}$ intravenously $\times 1$.

MASCC level of confidence: Moderate level of consensus: High ESMO level of evidence: II grade of recommendation: A

7. Recommended dose of neurokinin antagonists in MEC (unchanged since 2004)

The recommended dose of oral aprepitant in the prophylaxis of acute nausea and vomiting from MEC is $125 \mathrm{mg} \times 1$

MASCC level of confidence: Moderate level of consensus: High

ESMO level of evidence: II

grade of recommendation: A

8. The recommended dose of intravenous fosaprepitant in the prophylaxis of acute nausea and vomiting from MEC is $115 \mathrm{mg} \times 1$ (new since 2004)

MASCC level of confidence: Moderate level of consensus: High ESMO level of evidence: II grade of recommendation: A

9. The antiemetic effect of prophylaxis with a $5-\mathrm{HT}_{3}$ receptor antagonist plus dexamethasone declines during multiple cycles (more than 3 ) of MEC (unchanged since 2004).

MASCC level of confidence: High ASCO level of evidence: I level of consensus: High grade of recommendation: A
10. The effect of aprepitant in patients treated with AC is maintained during four cycles of chemotherapy (new since 2004).

$\begin{array}{ll}\text { MASCC level of confidence: High } & \text { level of consensus: High } \\ \text { ASCO level of evidence: I } & \text { grade of recommendation: A }\end{array}$

11. A dopamine antagonist can be used as supplement in the subsequent cycles in patients who experience nausea/emesis from MEC after treatment with standard antiemetic therapy $\left(5-\mathrm{HT}_{3}\right.$ receptor antagonist plus dexamethasone plus or minus a $\mathrm{NK}_{1}$ receptor antagonist) (unchanged from 2004).

MASCC level of confidence: Moderate level of consensus: High

ASCO level of evidence: II grade of recommendation: B

12. A benzodiazepine can be used as supplement in the subsequent cycles in patients who experience nausea/ emesis from MEC after treatment with standard antiemetic therapy $\left(5-\mathrm{HT}_{3}\right.$ receptor antagonist plus dexamethasone plus or minus a $\mathrm{NK}_{1}$ receptor antagonist) (unchanged from 2004).

MASCC level of confidence: Moderate level of consensus: Moderate ASCO level of evidence: II grade of recommendation: $\mathrm{B}$

Acknowledgement The 2009 MASCC/ESMO Antiemetic Guideline Update Consensus Meeting was funded by unrestricted grants from Eisai Inc, GlaxoSmithKline, Helsinn Healthcare SA, Merck \& Co. Inc., and Prostrakan Group. These sources had no role in the design, conduct, or results of the conference, nor in the preparation of data or this manuscript. Additionally, funding was received from the European Society of Medical Oncology (ESMO) and the Multinational Association of Supportive Care in Cancer (MASCC). MASCC organized the meeting. Individual members of either or both these organizations participated in the meeting and preparation of the manuscript.

Conflict of interest statement The following authors either received research funding, honoraria, or have been a consultant to, or an expert witness for:

Herrstedt: GSK, Helsinn, Merck

Rapoport: Merck

Warr: GSK, Merck

Roila: GSK, Helsinn, Merck

Bria: Helsinn, Merck

Rittenberg: Merck

Hesketh: GSK, Merck, Eisai

\section{References}

1. Antiemetic Subcommittee of the Multinational Association of Supportive Care in Cancer (MASCC) (2006) Prevention of 
chemotherapy- and radiotherapy-induced emesis: results of the 2004 Perugia International Antiemetic Consensus Conference. Ann Oncol 17:20-28

2. Apornwirat W, Albert I, Hansen VL, Bandekar RR, Grunberg SM (2009) Phase 2 trial results with the novel neurokinin-1 receptor antagonist casopitant in combination with ondansetron and dexamethasone for the prevention of chemotherapy-induced nausea and vomiting in cancer patients receiving moderately emetogenic chemotherapy. Cancer 115:5807-5816

3. Grunberg SM, Dugan M, Muss H et al (2009) Effectiveness of a single-day three-drug regimen of dexamethasone, palonosetron, and aprepitant for the prevention of acute and delayed nausea and vomiting caused by moderately emetogenic chemotherapy. Support Care Cancer 17:589-594

4. Herrstedt J, Koeller JM, Roila F, Hesketh PJ, Warr D, Rittenberg C, Dicato M (2005) Acute emesis: moderately emetogenic chemotherapy. Support Care Cancer 13:97-103

5. Herrstedt J, Muss HB, Warr DG, Hesketh PJ, Eisenberg PD, Raftopoulos H, Grunberg SM, Gabriel M, Rodgers A, Hustad CM, Horgan KJ, Skobieranda F, Aprepitant Moderately Emetogenic Chemotherapy Study Group (2005) Efficacy and tolerability of aprepitant for the prevention of chemotherapy-induced nausea and emesis over multiple cycles of moderately emetogenic chemotherapy. Cancer 104:1548-1555

6. Herrstedt J, Roila F, on behalf of the ESMO Guidelines Working Group (2008) Chemotherapy-induced nausea and vomiting: ESMO clinical recommendations for prophylaxis. Ann Oncol 19 (suppl 2):ii110-ii112

7. Herrstedt J, Apornwirat W, Shaharyar A et al (2009) Casopitant, a novel neurokinin-1 receptor antagonist, for the prevention of chemotherapy-induced nausea and vomiting: phase III trial results in patients receiving moderately emetogenic chemotherapy. J Clin Oncol 27:5363-5369

8. Italian Group for Antiemetic Research (2004) Randomized, double-blind, dose-finding study of dexamethasone in preventing acute emesis induced by anthracyclines, carboplatin, or cyclophosphamide. J Clin Oncol 22(4):725-729

9. Johnson B, Adams L, Lu E et al (2009) Impact of casopitant, a novel NK-1 antagonist, on the pharmacokinetics of ondansetron and dexamethasone. Support Care Cancer 17(9):1177-1185
10. Kris MG, Hesketh PJ, Sommerfield MR et al (2006) American Society of Clinical Oncology guideline for antiemetics in oncology: update 2006. J Clin Oncol 24:2932-2947

11. Lasseter KC, Gambale J, Jin B, Bergman A, Constanzer M, Dru $J$ et al (2007) Tolerability of fosaprepitant and bioequivalency to aprepitant in healthy subjects. J Clin Pharmacol 47 (7):834-840

12. McCrea JB, Majumdar AK, Goldberg MR et al (2003) Effects of the neurokinin antagonist aprepitant on the pharmacokinetics of dexamethasone and methylprednisolone. Clin Pharmacol Ther $74: 17-24$

13. NCCN Clinical Practice Guidelines in Oncology. Antiemesis V3.2009. http://www.nccn.org/professionals/physician_gls/PDF/ antiemesis.pdf

14. Rapoport B, Jordan K, Boice JA, Taylor A, Brown C, Hardwick JS, Carides A, Webb T, Schmoll H-J (2010) Aprepitant for the prevention of chemotherapy-induced nausea and vomiting associated with a broad range of moderately emetogenic chemotherapies and tumor types: a randomized, double-blind study. Support Care Cancer 18(4):423-431

15. Ruhlmann C, Herrstedt J (2009) Casopitant: a novel $\mathrm{NK}_{1}$-receptor antagonist in the prevention of chemotherapy-induced nausea and vomiting. Therapeutic Clin Risk Manag 5:375-384

16. Saito M, Aogi K, Sekine I et al (2009) Palonosetron plus dexamethasone versus granisetron plus dexamethasone for prevention of nausea and vomiting during chemotherapy: a doubleblind, double-dummy, randomized, comparative phase III trial. Lancet Oncol 10:115-124

17. Warr DG, Hesketh PJ, Gralla RJ, Muss HB, Herrstedt J, Eisenberg PD, Raftopoulos H, Grunberg SM, Gabriel M, Rodgers A, Bohidar N, Klinger G, Hustad CM, Horgan KJ, Skobieranda F (2005) Efficacy and tolerability of aprepitant for the prevention of chemotherapy-induced nausea and vomiting in patients with breast cancer after moderately emetogenic chemotherapy. J Clin Oncol 23:2822-2830

18. Yeo W, Mo FKF, Suen JJS et al (2009) A randomized study of aprepitant, ondansetron and dexamethasone for chemotherapyinduced nausea and vomiting in Chinese breast cancer patients receiving moderately emetogenic chemotherapy. Breast Cancer Res Treat 113:529-535 